\title{
Computer Users Perceptions of Indonesian Online Bussines Webpage Based on Human Computer Interface
}

\author{
Made Sudarma \\ Computer System and Informatics, Department of Electrical Engineering, \\ Faculty of Engineering, Udayana University
}

\begin{tabular}{l} 
Article Info \\
\hline Article history: \\
Received Jun $12^{\text {th }}, 2015$ \\
Revised Aug $20^{\text {th }}, 2015$ \\
Accepted Aug $26^{\text {th }}, 2015$ \\
\hline
\end{tabular}

Keyword:

Computer Human Interface

Online Bussines

E-Commerce

Webpage

\begin{abstract}
Nowadays, in this era of information technology personal computer is common usage in office and home purposes. Most of personal computer software applications use US-English for its user interface and not all countries use the computer instruction using the language of the country concerned. In general, the problem caused by conditions like this one is creates a semantic gap. Indonesian is also experiencing these problems which there are still many Indonesian people that cannot understand in computer English instructions. This gap may increase intensifies globalization. However, the semantic gap also creates end users market opportunity for Indonesian computer application with appropriate terminology. With proper terminology, making computer software applications will target of nonadvanced users. This paper researches on the potentials of an Indonesian online bussines web browser. A mocked-up clone of Mozilla Firefox 18.1 was made for the purpose of collecting questionnaire result from respondents. The respondents were computer course students which meet the criterions of non-advanced users. The test that was done states that simple straightforward translations should be adequate for most cases, although a standardization of terminologies is still required.
\end{abstract}

Copyright $@ 2016$ Institute of Advanced Engineering and Science. All rights reserved.

\section{Corresponding Author:}

Made Sudarma,

Computer System and Informatics,

Department of Electrical Engineering,

Faculty of Engineering, Udayana University.

Bali, Indonesia. Phone/Fax: 62361703315

Email: sudarma@ee.unud.ac.id

\section{INTRODUCTION}

\subsection{Background}

The rapid world-wide web developments encouraging of the services proliferation which is offer the use web-based display server applications. This has led to the growing importance of the position of the web browser on a personal computer. The user interface aspect is important role for end-user applications (Frank and Richard, 2001). It also said these types of applications are more concerned with the various aspects of the user as easy to learn, speed and ease of doing work, aesthetics, and other support facilities are provided rather than the quality of the algorithms, performance, or superiority theoretical [1].

Software instructions, the majority use English as the instructions so that many computer terminology written in English. Thus much of the terminology is difficult to find a counterpart in the Indonesian language [2]. Therefore there should be an experiment that could help establish Indonesian standard terminology translation. In Indonesia, the low level of education and the lack of ability to speak English with appropriate terminology users have resulted in a hidden problem that can grow along with the intense globalization. This causes the semantic gap between the users and application programs [3]. On the 
other hand, this problem is also given an opportunity for the development of software application programs in Indonesian appropriate terminology, especially for the end-user.

\subsection{Research Objectives}

The objectives and benefits of this study aim to:

1. Getting user's perception of the online bussines web browser Indonesian instruction.

2. Getting common terminologies in online bussines web browser Indonesian instruction.

3. The results of this study can be used as a reference for the computer application programs development base on terminology and user computer interface.

4. The perception of users is expected useful help the computer programmer to develop of application programs based on user centered design.

\subsection{Research Hypothesis}

With the selection of the Indonesia computer terminology, so that user and computer programmer working on similarly conceptual.

\section{LITERATURE REVIEW}

The Internet is a network technology of computers group that are connected to each other's so that all can share the information. Local Area Network (LAN) is a kind of computer network that is located in a single building or in a specific place, while the other computer network that connects computers located in faraway places called Wide Area Networks (WAN's) [4]. The Internet is the largest computer network in the world which is a lot of computers that interconnected and managed in a host-server.

The World Wide Web (www) is a part of network that most commonly used internet and that can accommodate graphics user interface. At first site is a collection of static documents that contain hyperlinks pieces of text and shown underlined that takes readers to other documents when clicked on. These documents are created in HTML, a hypertext markup language [5]. Now the web has evolved into an Internet-based multimedia network that provides a variety of facilities ranging from a series of static documents, online transactions, broadcast audio / video, or interactive multimedia. A web browser is a program that is run on the computer client that is used to retrieve and then display the web documents. Generally, a web browser that supports in HTML document into the main document format on the web, as well as several common image formats such as GIF and JPEG. In taking documents, web browsers interact with web server with HTTP protocol (Hypertext Transfer Protocol) [6]. An individual websites supported image formats and an HTML document as in Figure 1 which is consists of many web pages. In order to read the web page required a web browser, such as Netscape Navigator software, Internet Explorer, or Mozilla Firefox from Microsoft.

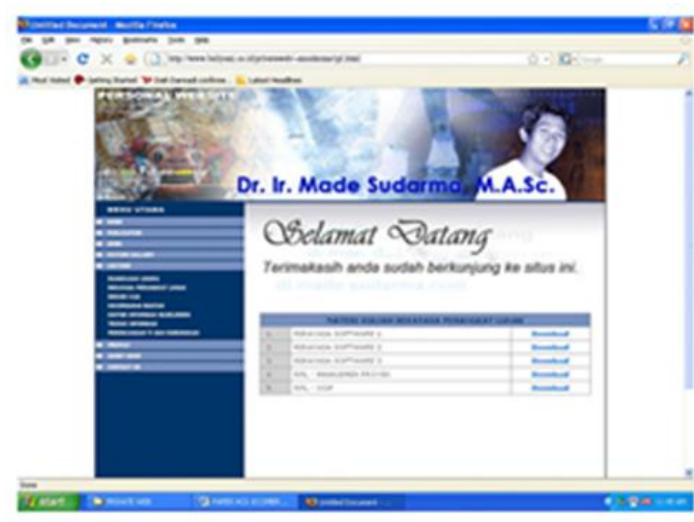

Figure 1. Personal Education Webpage

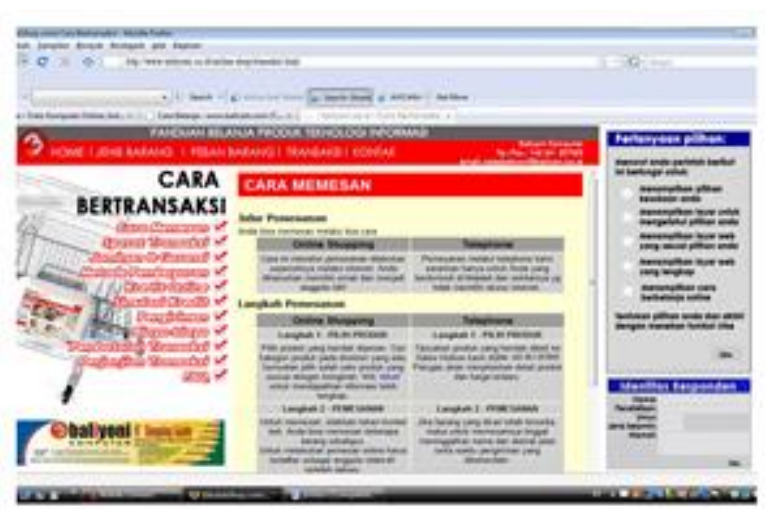

Figure 2. Indonesian Online Shopping Webpage

Online businesses commonly called electronic commerce (e-commerce) is a rapidly growing form of service in the internet world. The use of e-commerce can benefit many people, both consumers and producers and sellers (retailers) [7]. In Indonesia, online bussines systems are less popular because many internet users who still doubt its safety and lack of their commercial webpage terminology. The e-commerce 
transactions are not just a transaction of goods and money, but it's also needs transaction information, knowledge and services [8]. Online shopping gives many conveniences and advantages compared to the conventional transactions. In addition, online shopping can be spending time shorter, on the internet there are various kinds of goods are sold in full. Information regarding these items are also available, so although not buy it online, one can obtain the information needed to select the product to be purchased. Figure 2 below is a view of Indonesian online shopping webpage design.

In order for users and computers can interact with each other, so users feel the hospitality of the computer system to it, we need a media that allows the interaction takes place. Dialogue media based on textual and graphical design; however the textual-based dialog appears not so favored, because it looks stiff or inflexible and not interesting. Because it is developing a kind of graphical interface are known as GUI (Graphic User Interface). GUI was developed in 1990, allows users to search, display, and store the information that is the Internet [9]. GUI systems such as hows in Figure 2, does not define a look-and-feel. User interface elements submitted on application-level library commonly called toolkits [10]. Based graphical interface on the one hand was very attractive but on the other hand also becomes very difficult to implement.

The web programming written by Ruby on Rails (RoR), which the RoR is a framework for building web-based system. Rails is its framework and the Ruby is a programming language [11]. The advantages of using RoR framework is the speed of the application development and also practicing self-discipline to write code for programmers because this framework has an elbow strict rules [12]. With the existence of this rule will facilitate the process of maintenance depends on the application without a programmer only. In other words, system maintenance can be done by other computer programmers, as long as they understand the rules of RoR, then they will be able to continue the work of previous programmers. Furthermore, the questionnaire program is modeled to follow the appearance Mozilla Firefox ${ }^{\text {TM }} 18.1$, which is a web browser that is simple but has enough functionality for the beginers user. This control component has size (code size) is relatively small, simple, and has been included in PHP [13][14] and MySQL [15]. Thus the essence of the program is a window frame that provides support for this component interface. The program is intended for Win32 ® platform for PC users beginer using the operating system such as Windows ${ }^{\mathrm{TM}}$ 7, which has good stability thus strongly supports the development of software that is trial-and-error when debugging. Nonetheless, online shopping program created using the Indonesian computer instructions can be executed on the system platform.

\section{RESEARCH METHODS}

In this study, a questionnaire was given to users (respondents) interactively using the Mozilla Firefox 18:01 web browser. When a menu item is selected, the respondent filed a dialog that displays the question of the function of the choice question. In the form of multiple choice questions, consist four possible answers for each question. At each appearance questions, randomized sequences response to reduce the things that are not meaningful in the study.

The analysis and flow of analysis in this study can be described as the following bellow:

1. Data were analyzed using hypothesis testing goodness-of-fit. Each option is given a value expected response frequency chosen by the authors: in which the answer with the highest frequency is considered the most correct answers by the authors, while the lowest frequency response is considered correct at least.

2. Tests performed by Chi-Square distribution with a level of significance of $1 \%("=.01)$. Hypothesis Null (H0) is the answer of respondents would vote in accordance with the truth value chosen by the author. Truth value of a response is indicated by the expected frequency of the response. Alternative Hypothesis (H1) is generally considered correct answers by the respondents differ with the author.

$$
X^{2}=\sum\left[\frac{\left(O_{i}-E_{i}\right)^{2}}{E_{i}}\right]
$$

Chi-Square equation:

$\mathrm{X} 2=$ Chi-Square value

$\mathrm{Oi}=$ number of respondents to answer specific questions

$\mathrm{Ei}=$ expected number of answers to that question

The research was conducted in accordance with the following research protocols:

1. Beginning with the identity of the respondents fills out the form

2. Determine: background, formulation of the problem, purpose of the reseach, research methods. 
3. Creating a view model interactive questionaries

4. Designing the initial display model

5. Designing the questionnaire questions, and tests the questions accuracy that relevant to the research

6. Creating a model to show the questionnaire

7. Perform compatibility testing system

8. If the questionnaire models is not compatible yet then returned to the initial models

9. However the questionnaire model is compatible then combining questionnaire module with the research questions.

10. The next step was like, collecting questionnaire data, process the data collected, formulating conclusions from the data that has been processed

11. If all the above steps have been completed then the study concludes with a research report.

\section{SAMPLE}

\subsection{Sampling}

In this experiment we determined earlier that the respondent (subject) is a person with no knowledge of computers. In general, the assumption of "laymen" is those who do not understand the use of computers in depth. For clarity, common assumptions can be defined as respondent (subject) who do not meet one or more of the following criteria:

a. Experience or working in the field of Information Technology or Electronic Data Processing.

b. Experience or studying or teaching at higher education institutions in computing, or engineering fields.

c. Experience or a carrier on a Bulletin Board System (BBS).

d. Experience to be administrator of the server installation that is connected to the LAN, WAN, or the Internet.

e. Experience or currently using UNIX ® based system shell (and its derivatives) in a daily basis.

f. Experience or understand the programming and can make a program using one programming language and application programming packages that have facilities (such as PHP, ASP, etc.).

\subsection{Sampling procedure}

Procedure in this study all respondents had to fulfill the following criteria:

1. Samples were taken at random from the respondents are directly or indirectly that meet the definition of ordinary. While reducing the level of randomness, how this should be done for a variety of resource limitations. The sample consisted of students D0, D1, D2, D3, and S1 at educational institutions in the municipality of Denpasar. The majority of the outside of the computer department or have knowledge or experience in the field of computer.

2. Sampling was conducted with the respondents to the computer and then asked to select all the menu options in the form of a question. Once respondents complete, the program will be closed questionnaire which will then generate a data file that contains answers to the questionnaire. The data file is then collected to be processed.

\section{RESULTS AND DISCUSSION}

In this study, sampling was conducted directly or indirectly due to filling out the questionnaire had to use a computer, so it is much easier if the respondent had known before. Of the 40 respondents who captured the majority of respondents expected from middle-and upper-class economy. While about threequarters of respondents expected from Bali ethnic tribes, the rest is a combination of various tribes. The Figure 4 shows the analysis of Chi-Sequere value perception respondents were in line with expectations. Of the 30 questions posed to respondents, result in 22 units $(72.53 \%)$ within their answers to the initial hypothesis. Analysis of the range is the lowest $2 \%$ - the highest is $7.47 \%$. Level of significance used was $1 \%$ $("=.01)$, while the three degrees of freedom $(\mathrm{DF}=3)$, and in accordance with the four possible answers to each question. While $26.51 \%$ is the answer to a question which is not in accordance with the initial hypothesis. Question -a question that is not answered is not included in the calculation.

In Figure 5 describes the results of the analysis are answers to questions that are not in line with expectations. Of 40 respondents who captured the 30 questions posed to the respondents i.e. $26.67 \%$ gave no answer as expected with the lowest analysis value of $12 \%$ and the highest $34.9 \%$. In a discussion based on estimates of the error that occurred and any options written back the number of answers that occur $(\mathrm{O})$ and the expectation of the answer (E) is as follows:

1. The reliability result of webpage software, involving 40 respondents found out that $68.2 \%$ of respondents said that webpage had a complete feature and $31.8 \%$ said that it had very complete feature; 
$72.3 \%$ said that was reliable and $27.7 \%$ said that it was very reliable; $42.3 \%$ said it was easy to use and $57.7 \%$ said it was very easy to use; $63.1 \%$ said it was safe and $36.9 \%$ said it was very safe; and $25.8 \%$ said it could document well and $74.2 \%$ said the documenting was very well.

2. Perceptions of respondents to list the contents of a variety of assistance offered. As much as $25.1 \%$ of respondents did not consider that the online help is part of the documentation program.

3. From the analysis of $33.59 \%$ of respondents were not aware that the context of windows is on a browser. Its means users generally thought that the window with the program did not consider that the program is actually an executable Windows Operating System.

4. As much as $25.17 \%$ of respondents gave very similar answers to other questions so the question becomes ambiguous.

5. Value analysis, $23.21 \%$ of respondents thought that the source is a web page. This means that respondents did not understand the concept of "source code" so no matter who chose the answer to that question.

6. Analysis results based on the respondents thought $27,87 \%$ of respondents are not aware of services like News, FTP, Ghoper, and Telnet. This is due to the respondents thought influenced by the popularity of web-based email like Yahoo. In addition many respondents who do not use search engines to other sites.

7. Hence there are a $15 \%$ of respondents rarely changed from the default start page. A word starting page is a translation of the start page turns ambiguous effect. The term initial appearance may be better to replace the start page.

8. Most respondents referred to the web browser as the internet and also may not notice the name of the program. In addition, not fewer respondents $(16.6 \%)$, which refers to the software package Microsoft Office and Internet Explorer with the Windows name.

9. The result finding $18,22 \%$ of respondent is quite difficult to be understood the concept of cut and paste so it is necessary to understand the concept of the clipboard is an area that is hidden in memory to store data.

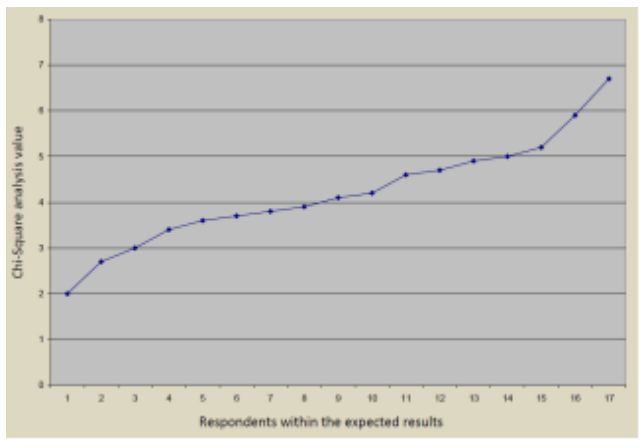

Figure 4. The Analysis Results as Expected

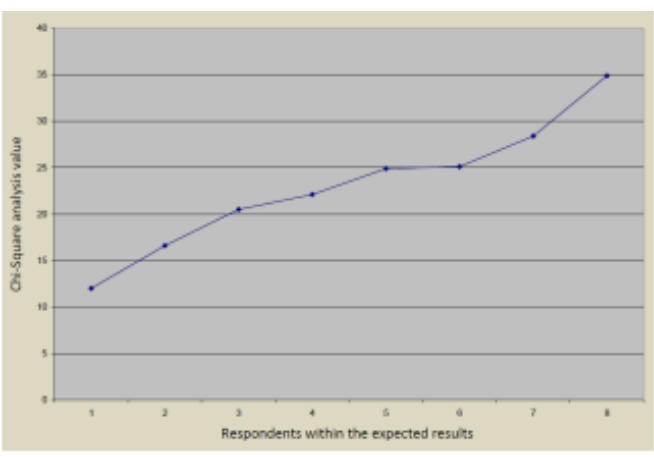

Figure 5. The Analysis Results of Mismatch Expectations

The significance of these results said that the success of an ecommerce web design determined by user interface and cognitive respondent [1]. Stated that online shopping is not just a transaction of goods and money, but also the user knowledge of the online transaction concept. That requires online bussines webpage design based on the user centered design so as to provide a positive impact on cognitive factors such online shopping webpage will be much easier to understand and use. The results also illustrate still less popular online shopping among the respondents, because many of them lack knowledge and the weak of online transactions security [8].

\subsection{Research Weaknesses}

In this study found few constraints in making the interface as follows:

1) There is no equivalent term in the computer translation dictionaries, including some very unsuitable equivalent word in the perception of the user, thereby causing difficulty finding the computer terms in Indonesian.

2) Interactive questionnaire method that uses a computer can inhibit the mobility of data collection, thereby causing limited and less random sampling. 
3) Most of the respondents complained that to answer the questions they need to rethink the original computer terms in English. This might be due to the limited term or computer terminology in Indonesian.

\section{CONCLUSION AND RECOMMENDATIONS}

6.1. Conclusion

1. Translating the computer with the user interface elements of the English into Indonesian is sufficient for most cases, but to facilitate the development of computer software applications in the long term Indonesian standardization is still needed.

2. Computer users from middle and upper economic levels, more able to use the English language as a computer interface. Based on informal discussions with some respondents, they have their own hatred against Indonesian user interface.

3. This study is a preliminary study, in which the results are still not able to represent the general public, because there are many users who were in the heterogeneity of the samples.

\subsection{Recommendations}

1. There needs to be further research with a sample of more and more representative and reproduced features of the application software. With models of different applications that further research should be categorized according to various user roles for the application in question.

2. It needs to make the user interface guidelines for software applications in Indonesian language so there will be a proper standardization of computer terms and Indonesian terminology that is easily understood.

\section{REFERENCES}

[1] Frank E.R. and Richard, M.Y. (2001). Embodied Models as Simulated Users: Introduction to this Special Issue on Using Cognitive Models to Improve Interface Design. International Journal Of Human Computer Studies. pp.1-14

[2] Dyson, P. (1994). Kamus Komputer. Alih bahasa, Surya Satyanegara. Jakarta: Arcan.

[3] Barnard, P. J., May, J., Duke, D. \& Duce, D. (2000). Systems, Interactions, and Macro Theory. ACM Transactions on Computer Human Interaction, 7, pp. 222-262.

[4] Tanenbaum, A.S. 1996. Computer Networks, 3rd edition. New Jersey: Prentice-Hall International Editions.

[5] Purwanto, E. (2002). Pengantar World Wide Web. Jakarta: Jaringan Informasi IPTEK, JIIPP.

[6] Prihatna, H. (2005). Kiat Praktis Menjadi Web Master Profesional. Jakarta: Penerbit PT. Elex Media Komputindo.

[7] Suyanto, M. (2005). Strategi Periklanan pada E-Commerce. Yogyakarta: Andi Offset

[8] Purbo, O.(2005). Knowledge Commerce. Perpustakaan Onno. Accessed 21 Nopember 2012 http://stream.plasa.com/onno/gfe/index.php?dir=artikel_indonesia_1/application/e-commerce

[9] Tuck, Mike. (2001). the Real History of the GUI. WebmasterBase.Com. accessed 15 November 2012 http://www.webmasterbase.com/printTemplate.php?aid=511.

[10] Kimball, P.E. (1995). The X Toolkit Cook Book. New Jersey: Prentice Hall International Editions.

[11] Ruby, S. et. al.(2011) Ruby Programming Language, Accessed 1 August 2012 http://en.wikipedia.org/wiki/Ruby_\%28programming_language\%29

[12] Hartl, M., (2011). Ruby on Rails Tutorial: Learn Web Development with Rails, Accessed 21 Nopember 2012 http://ruby.railstutorial.org/chapters/beginning

[13] Castagnetto, J., Rawat, H., Schumann, S., Scollo, C., Veliath,D. (1999). Professional PHP Programming. Jakarta: Penerbit Wrox Press Ltd.

[14] Lukmanul, H., dan Musalini. (2004). 150 Rahasia dan Trik menguasai PHP. Jakarta: PT Elex Media Komputindo.

[15] Raymond, A.L., and Daudenarde, J.J. (1991). SQL and Its Applications. New Jersey: Prentice Hall.

[16] Microsoft Corporation, (2000). Microsoft Developer's Network CD, February 2000 edition. 